Article

\title{
Dye-sensitized Photocatalyst of Sepiolite for Organic Dye Degradation
}

\author{
Chitiphon Chuaicham, Radheshyam Pawar and Keiko Sasaki *(i)
}

Department of Earth Resources Engineering, Faculty of Engineering, Kyushu University, 744 Motooka, Nishiku, Fukuoka 819-0395, Japan; song@mine.kyushu-u.ac.jp (C.C.); pawar@mine.kyushu-u.ac.jp (R.P.)

* Correspondence: keikos@mine.kyushu-u.ac.jp; Tel.: +81-92-802-3338

Received: 10 January 2019; Accepted: 26 February 2019; Published: 4 March 2019

check for updates

\begin{abstract}
The photocatalytic activity of sepiolite was examined for degradation of several dye compounds under visible light irradiation. Higher adsorption capacities and greater photocatalytic performance of cationic dyes (rhodamine B and methylene blue) were observed on sepiolite, in comparison with anionic dyes (orange II and trypan blue). Superiority in the photocatalytic activity of cationic dyes is attributed to the strong electrostatic attraction and photosensitization properties of cationic dye molecules. Sepiolite has degraded $45.3 \%$ rhodamine B within $120 \mathrm{~min}$, which is the greatest photocatalytic degradation efficiency when compared with other dyes. Subsequently, the reusability of spent sepiolite after adsorption of rhodamine B was evaluated by the degradation of trypan blue under the visible light irradiation. The photocatalytic degradation performance of trypan blue by spent sepiolite after adsorption of rhodamine B increased about twice as much as with pristine sepiolite, indicating that the dye-sensitized photocatalytic process could enhance the photocatalytic degradation ability of sepiolite. Through radical scavenger tests, it was found that a superoxide radical is mainly responsible for rhodamine B degradation. The possible mechanism of rhodamine B degradation under visible light irradiation was proposed. The sepiolite could be a potential catalyst for the degradation of organic pollutants in wastewater under solar light.
\end{abstract}

Keywords: sepiolite; photocatalyst; organic dye degradation; dye-sensitized photocatalytic process

\section{Introduction}

Naturally abundant 2:1 type of clay minerals, representatively smectite, have been extensively used as support materials for semiconductors or other photocatalysts due to its natural abundant availability and characteristics features, such as, fibrous or layered morphology, large specific surface areas, superior cation exchange capacity, negative surface charge, and a hydroxyl group rooted at the bottom in the octahedral sheet [1-5]. Comprehensively, all these natural properties can be utilized for several types of organic and inorganic types of modifications which are benefited to the development of clay-based photocatalyst [6,7]. In recent years, natural sepiolite, belonging to the 2:1 type of clay minerals, has gained great interest in different fields of application, including the development of photocatalyst [8-10]. Sepiolite is a hydrous magnesium silicate that is widespread due to its unusual fibrous morphology and intracrystalline tunnels [11,12]. The ideal chemical formula is expressed as $\mathrm{Si}_{12} \mathrm{Mg}_{8} \mathrm{O}_{30}(\mathrm{OH})_{4} \cdot 12 \mathrm{H}_{2} \mathrm{O}$ for the half-unit cell. In the structure of sepiolite, there is an alternation of blocks and tunnels around $200 \AA$ in pore size that grows up in the direction of fibers belonging to a chain type of clay mineral [13]. Each structural block is composed of a central octahedral sheet containing magnesium sandwiched by two tetrahedral silicate sheets. The structure of sepiolite results in zeolite-like channels [14]. The peculiar pore structure with interior channels contributes to voluminously adsorb cationic organic molecules and ions. In addition, these channels might contain 
zeolitic water and exchangeable metal ions. The structural and textural physicochemical properties of sepiolite offer its exclusive role compared to other clay materials.

So far, sepiolite has been considered as an effective hole transporter between known semiconductor materials and degrading targets in the photocatalytic reaction to decompose organic pollutants, including organic dyes and pharmaceutical wastes. Many $\mathrm{TiO}_{2}$-based composites have been developed to improve photodegradation using a sepiolite matrix: ternary heterogeneous $\mathrm{BiOCl} / \mathrm{TiO}_{2}$ /sepiolite composite for tetracycline degradation [15], sepiolite- $\mathrm{TiO}_{2}$ nanocomposites for the orange $\mathrm{G}$ dye degradation [16], $\mathrm{TiO}_{2}$ / sepiolite composites for the degradation of acid red $\mathrm{G}$ and 4-nitrophenol [17], and $\mathrm{TiO}_{2}$ /sepiolite composites to decompose phenol [18]. Composites with other metallic oxides and hydroxides have been also synthesized for photodegradation of organic dye compounds: Sepiolite@LDH composite for simultaneous photocatalytic degradation of methyl orange (MO) and methylene blue (MB) dye [19], ternary $\mathrm{ZnO} / \mathrm{Fe}_{3} \mathrm{O}_{4}$-sepiolite nanostructured material for MB dye degradation [20,21], and quantum-sized $\mathrm{ZnO}$ particles on sepiolite for the degradation of reactive blue 4 [22]. So far, from the above reports, sepiolite has been generally utilized as an efficient supporting material for well-known semiconductors and other types of photocatalytically active species under UV light irradiation.

Fibrous morphologies of sepiolite offer the rigid and active surfaces for the adsorption of cationic dye molecules through electrostatic interaction or complexation. Successful adsorption of dye molecules on clay surfaces is indispensably the first step for photocatalytic reactions [23-25]. Siloxane bonds are existing at the edge of the outer surface, and broken and terminated $\mathrm{Si}-\mathrm{O}$, and $\mathrm{Mg}-\mathrm{O}$ bonds are on lateral surfaces of sepiolite. Since these unprotected metallic ions at the edges are electron-deficient, they are expected to act as natural electron acceptors. The adsorbed cationic dye species, which are electro-statistically bound with the broken bond surface, should be responsible for the generation of dye radical species. It is predictable that the formed dye radicals can react with active oxygen species present within the system, which may lead to a disintegration of the dyes [26]. In addition, it is well-known that the highly polar surface of the clay material is advantageous to stabilize the generated radical species, which prolongs lifetime and ultimately causes better photocatalytic performance [6].

As aforementioned, sepiolite was utilized as supporting material for well-known photocatalysts $\left(\mathrm{TiO}_{2}, \mathrm{BiOCl}, \mathrm{ZnO}\right.$, etc.). As per our knowledge, there was no report available on the dye-sensitization of natural sepiolite. In this work, we tried to fulfill the understanding of natural sepiolite as a dye-sensitized photocatalyst for dyes degradation. The observed phenomenon was proved by several physiochemical and photocatalytic experimental studies in the presence of different dyes with various size and charges, e.g., anionic or cation colorants organic pollutants. One of the important findings in the present work was that natural sepiolite material without any modification could be utilized for the photocatalytic degradation of organic dye via the dye-sensitization mechanism.

The detail objectives in the present study were to investigate the visible light-driven photocatalytic degradation performance of the natural, pristine sepiolite for cationic (rhodamine $\mathrm{B}(\mathrm{RhB})$ and $\mathrm{MB}$ and anionic (orange II (OII) and trypan blue (TB)) dyes and to propose the mechanism based on the experimental results.

\section{Results and Discussion}

\subsection{Characterizations}

As received, the sepiolite was confirmed by several characterization techniques, including XRD, FTIR, TEM, XRF, specific surface area measurement, and XPS analysis. As shown in Figure 1a, the specimen had an apparently single phase of sepiolite in the XRD pattern (Joint Committee on Powder Diffraction Standards (JCPDS) 13-0595). There were trace amounts of impurities of Ti, Fe, and Al, confirmed by XRF (Table 1). The purity as sepiolite $\left(\mathrm{Si}_{12} \mathrm{Mg}_{8} \mathrm{O}_{30}(\mathrm{OH})_{4}\right)$ could be estimated to $89.9 \%$, based on Mg content. The XRD results showed several reflections, such as the strong diffraction peaks, 
for pure sepiolite observed around d-spacing value $1.2 \mathrm{~nm}$ at $2 \theta=7.3^{\circ}(110)$, which represent the characteristics interlayer distance reflection for sepiolite clay. And another characteristics reflection peaks for the pure phases of sepiolite clay was observed at $0.75 \mathrm{~nm}$.at $2 \theta 11.83^{\circ}(130), 0.66 \mathrm{~nm}$ at $2 \theta 13.12^{\circ},(040), 0.45 \mathrm{~nm}$.at $2 \theta 19.71^{\circ}(060), 0.43 \mathrm{~nm}$. at $2 \theta 20.66^{\circ}(031), 0.375 \mathrm{~nm}$.at $2 \theta 23.74^{\circ}$ (221), $0.334 \mathrm{~nm}$.at $2 \theta 26.71^{\circ}(400)$, and $0.25 \mathrm{~nm}$.at $2 \theta 35.01^{\circ}$ (191), which confirmed the presence of pure phases of sepiolite [27].
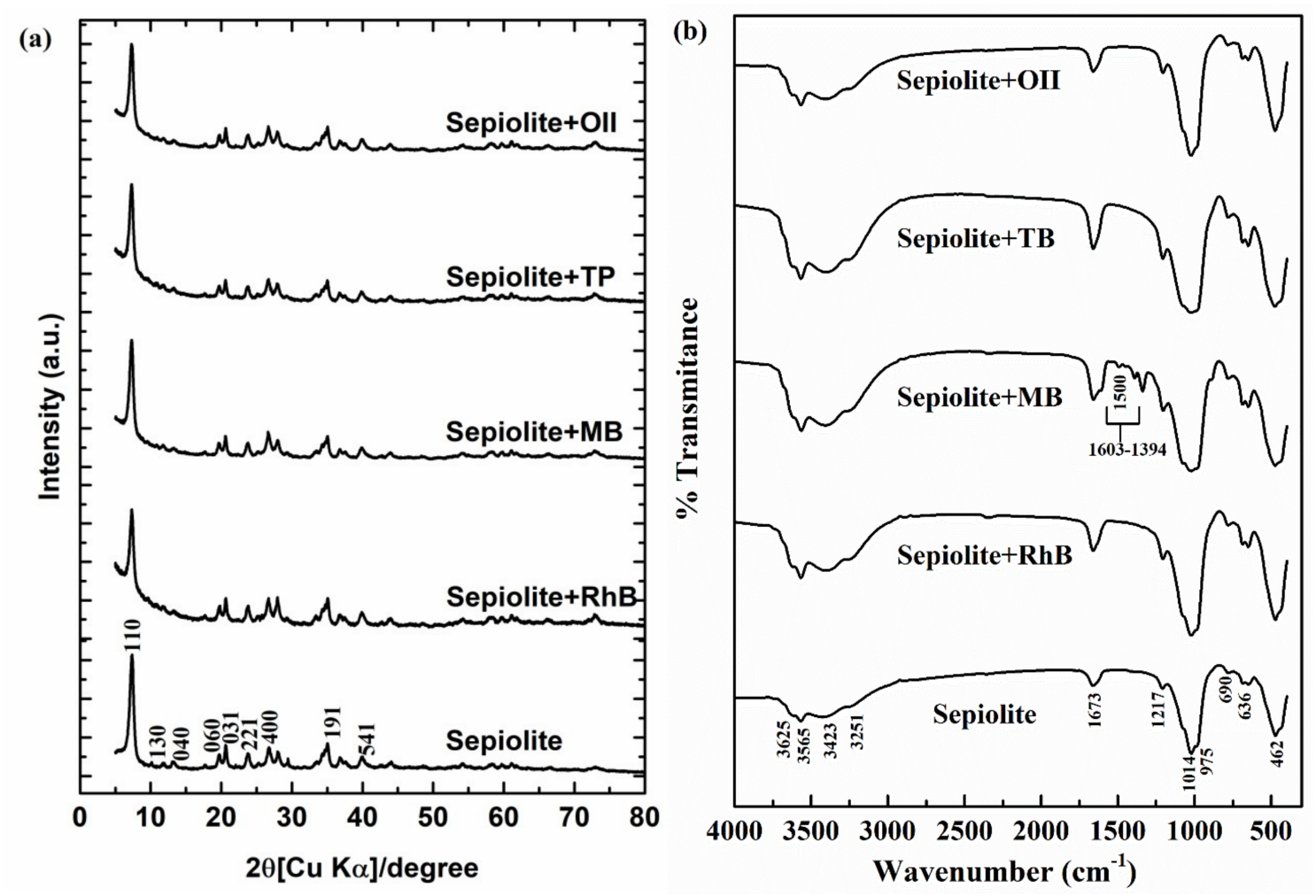

Figure 1. (a) PXRD patterns and (b) FTIR spectra of sepiolite and the spent sepiolite after photocatalytic degradation in various organic dye compounds.

Table 1. The elemental compositions of sepiolite in wt.\%.

\begin{tabular}{ccccccccccc}
\hline Component & $\mathbf{C}$ & $\mathbf{N}$ & $\mathbf{O}$ & $\mathbf{F}$ & $\mathbf{N a}$ & $\mathbf{M g}$ & $\mathbf{A l}$ & $\mathbf{S i}$ & $\mathbf{P}$ & $\mathbf{S}$ \\
\hline wt.\% & 6.817 & 0.339 & 53.459 & 0.864 & 0.047 & 13.182 & 1.087 & 23.235 & 0.007 & 0.011 \\
\hline Component & $\mathbf{C l}$ & $\mathbf{K}$ & $\mathbf{C a}$ & $\mathbf{T i}$ & $\mathbf{M n}$ & $\mathbf{F e}$ & $\mathbf{C u}$ & $\mathbf{Z n}$ & $\mathbf{Z r}$ & $\mathbf{B a}$ \\
\hline wt. $\%$ & 0.017 & 0.435 & 0.135 & 0.054 & 0.011 & 0.265 & 0.002 & 0.009 & 0.001 & 0.019 \\
\hline
\end{tabular}

The FTIR spectrum of the pristine sepiolite clay mineral was observed in Figure $1 \mathrm{~b}$ similarly to that reported in the literature for 2:1 smectite clay minerals by a slight variation in the frequencies [28,29]. The bands observed in the range of 3000 and $3800 \mathrm{~cm}^{-1}$ were assigned to the stretching vibration mode of the hydroxyl groups in $\mathrm{Mg}-\mathrm{OH}$. The peak centered at $3625 \mathrm{~cm}^{-1}$, attributed to $\mathrm{OH}$ stretching mode. The absorption bands centered at about 3423 and $3251 \mathrm{~cm}^{-1}$ corresponded to the vibration mode of physisorbed water (surface and zeolitic); a band at $1673 \mathrm{~cm}^{-1}$ due to the bending mode of zeolitic water; bands in the $1200-400 \mathrm{~cm}^{-1}$ range characteristic of silicate; bands centered at 1014 and $462 \mathrm{~cm}^{-1}$ due to stretching in the vibration mode of $\mathrm{Si}-\mathrm{O}-\mathrm{Si}$ groups in the tetrahedral sheet; bands at 1217 and $975 \mathrm{~cm}^{-1}$ due to Si-O bonds; and bands at 690 and $639 \mathrm{~cm}^{-1}$ corresponding to the vibration mode of $\mathrm{Mg}-\mathrm{OH}$ bond [29].

TEM images for the pristine sepiolite showed straightly fibrous shapes with several hundred $\mathrm{nm}$ to $1 \mu \mathrm{m}$ in length and 50-60 $\mathrm{nm}$ in width (Figure 2). It was clear that the crystal was developed 
in a one-dimensional direction [30]. The nitrogen sorption isotherm plot is presented in Figure 3a. The isotherms represented type IV isotherm nature, with a narrow H3-type of hysteresis loop, according to the International Union of Pure and Applied Chemistry (IUPAC) classification [31,32]. The H3 type of hysteresis loop is characteristic of the pore channels in the layers of smectite clay minerals $[29,33,34]$. A comparative pressure range from 0.7 to 1.0 would indicate that a crack-type mesoporous structure exists in pristine sepiolite [35]. Additionally, the isotherm was unsaturated near to 1.0 relative pressure $\left(\mathrm{P} / \mathrm{P}_{0}\right)$. The Barrett, Joyner, and Halenda method $(\mathrm{BJH})$ pore size distribution plot is presented in Figure $3 \mathrm{~b}$, suggesting that pore structure in the sepiolite was an irregular type. The Brunauer-Emmett-Teller (BET) specific surface area of pristine sepiolite was observed around $230 \mathrm{~m}^{2} / \mathrm{g}$ and the total pore volume of $0.686 \mathrm{~cm}^{3} / \mathrm{g}$ was determined by BET method.

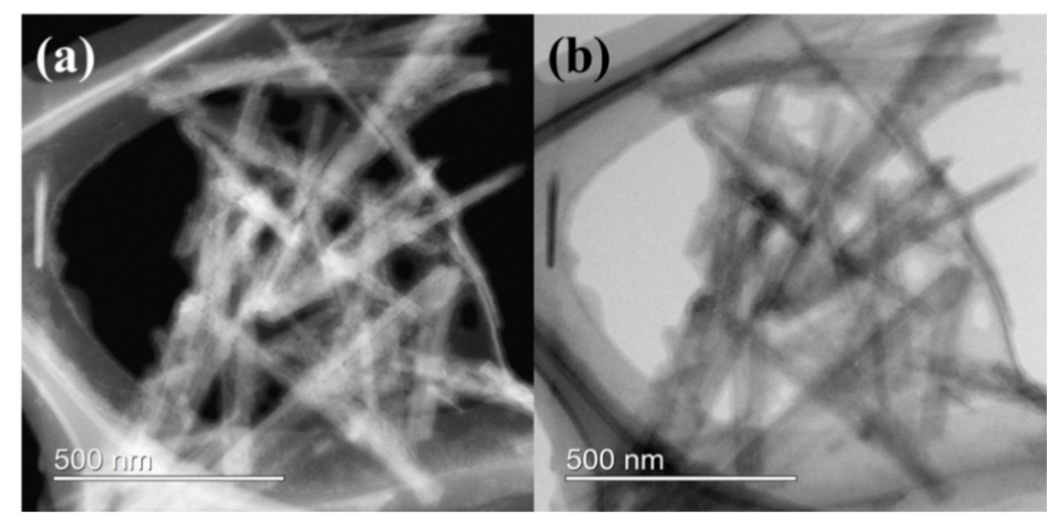

Figure 2. TEM images of sepiolite. (a) Bright-field and (b) dark-field; scale bars indicate $500 \mathrm{~nm}$.
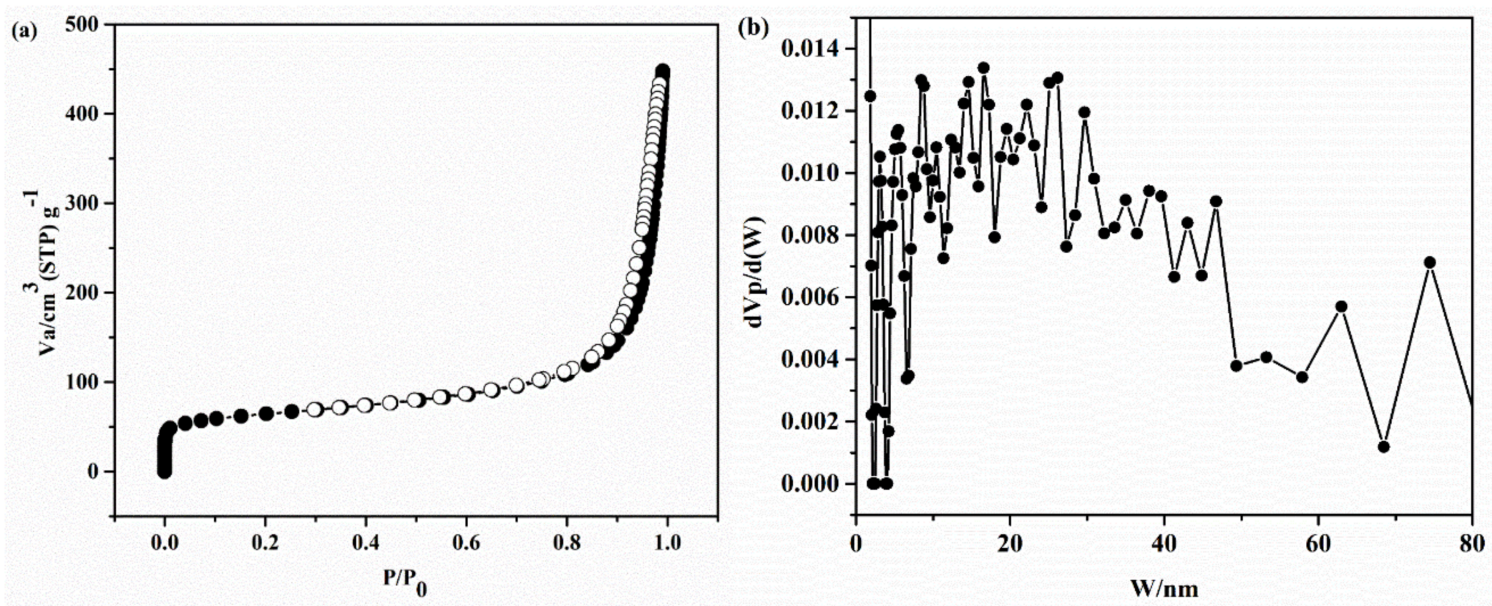

Figure 3. (a) Nitrogen adsorption-desorption isotherm and (b) BJH pore size distribution for sepiolite.

The XPS measurements were carried out to elucidate the elemental compositions and electronic properties of sepiolite. In Figure $4 a$, the survey spectrum for the pristine sepiolite shows the predominant peaks assigned to $\mathrm{Si} 2 \mathrm{p}, \mathrm{O} 1 \mathrm{~s}$, and $\mathrm{Mg} 2 \mathrm{p}$ orbitals and a small peak assigned to $\mathrm{Al}$ $2 p$. The valence band (VB) energy can be estimated to around $2.81 \mathrm{eV}$ by drawing the straight tangent line to the VB spectrum of the sepiolite as shown in Figure $4 b[36,37]$. 

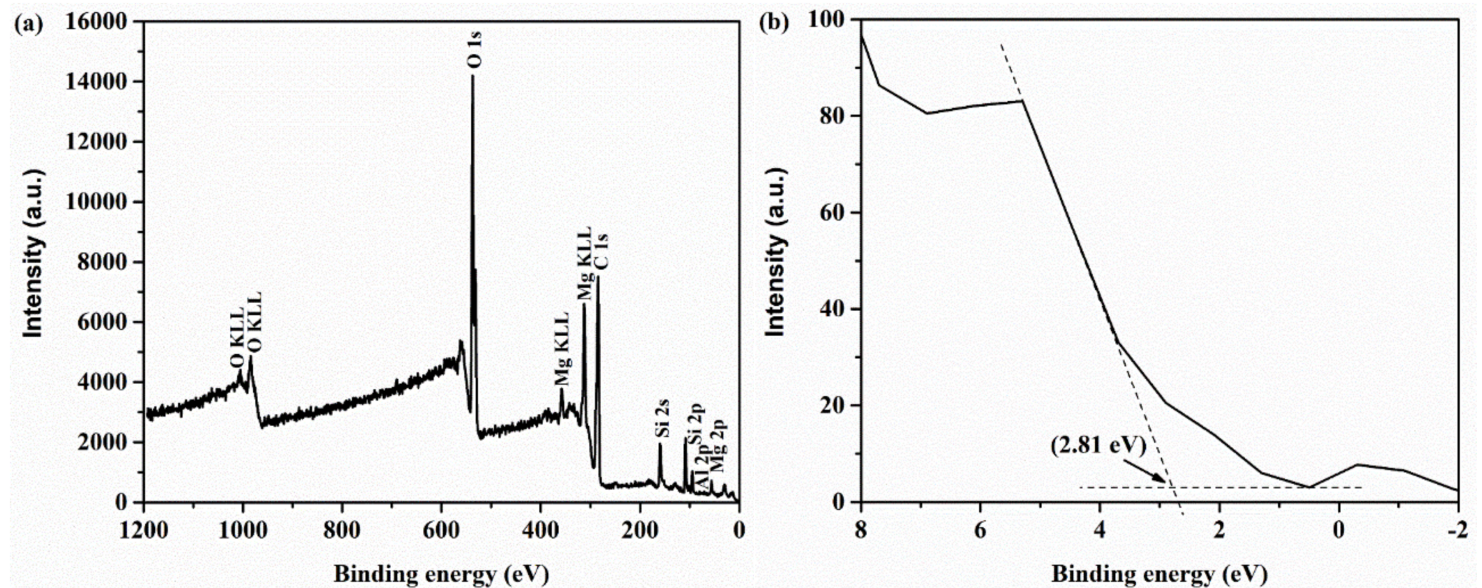

Figure 4. XPS spectrum of sepiolite. (a) Survey scan and (b) valence band (VB) energy region.

Figure 5a shows the UV-Vis diffuse reflectance spectrum (UV-DRS) of sepiolite. It was observed that the absorption of sepiolite had photo-responses from the UV to the visible light region. In addition, sepiolite has shown a light absorption predominantly around $300-350 \mathrm{~nm}$, indicating that sepiolite can be excited under the ultraviolet light irradiation. The optical band gap energy $(E g)$ of a semiconductor photocatalyst can be evaluated by using the Kubelka-Munk equation [38]:

$$
\alpha h v=A(h v-E g)^{n / 2}
$$

where $\alpha, h, v, E g$, and $A$ are the absorption coefficient, Planck constant, light frequency, band gap energy, and the proportionality constant, respectively. In addition, $n$ is dependent on the type of optical transition of semiconductor ( $n=1$ for direct transition and $n=4$ for indirect transition). The band gap energy value was calculated by the linear part of the $(\alpha h v)^{2}$ versus energy $(E g)$ plot. Based on the UV-DRS results, the band gap energy of sepiolite could be estimated to be $3.7 \mathrm{eV}$ through the Tauc plot (Figure 5b). Therefore, the conduction band energy (CB) of sepiolite could be calculated to be $-0.89 \mathrm{eV}$.
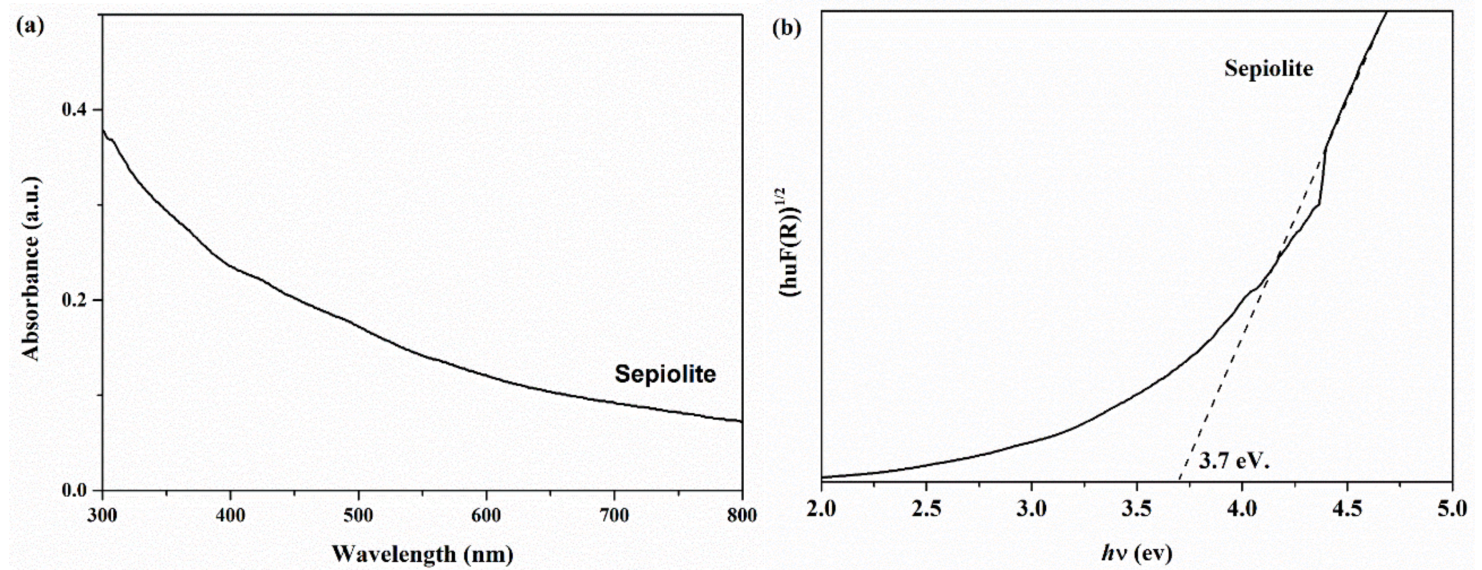

Figure 5. UV-Vis spectrum of sepiolite. (a) Diffuse reflectance spectrum (DRS) spectrum and (b) Tauc plot.

\subsection{Photocatalytic Activity for Organic Dye Degradation}

Organic dyes, MB, RhB, OII, and TB were used as models of organic pollutants to estimate the photocatalytic performance of sepiolite under the visible light irradiation. The adsorption capacity of each organic dye compound on sepiolite was determined under the dark condition without the visible light irradiation. Figure 6a displays the removal efficiency results of organic dyes by sepiolite 
under the dark (dotted lines) and visible light (solid lines) irradiation. In dark control, the sepiolite showed a higher adsorption capacity of cationic dyes, MB and RhB, than anionic dyes, OII and TB. It could be explained by electrostatic interaction of the cationic dyes with sepiolite, which is negatively charged so that the cationic dye molecules are strongly attracted through ion exchange with mainly $\mathrm{K}^{+}[3,4,39]$. However, the adsorption density was saturated within 30 min under the dark condition. Prior to photocatalytic reaction under the visible light, the suspension of sepiolite particles was well-dispersed by stirring under dark for $30 \mathrm{~min}$ in order to achieve the adsorption-desorption equilibrium. Immediately after the visible light was irradiated, sepiolite particles exhibited the photocatalytic degradation of cationic dyes in contrast to anionic dye molecules.
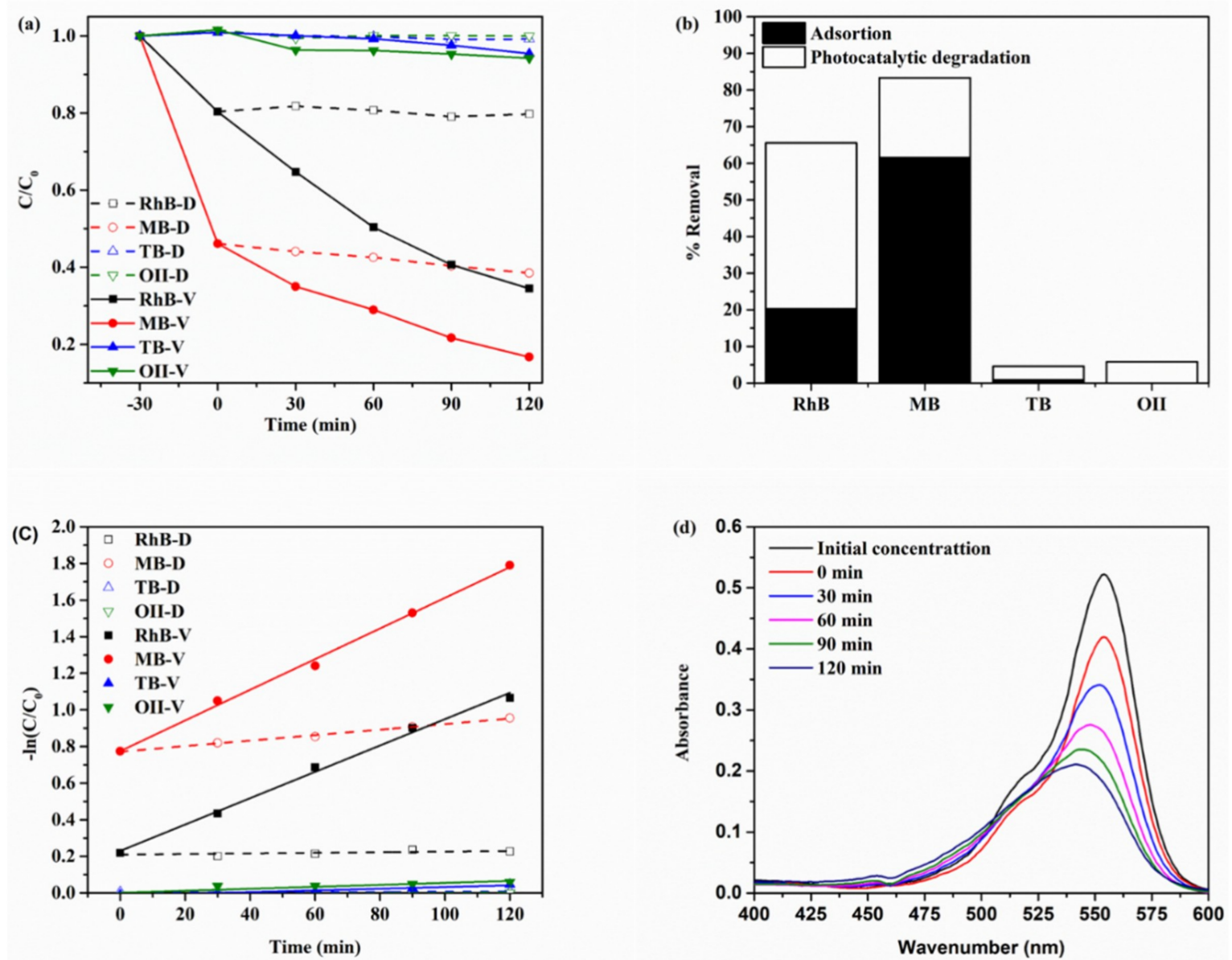

Figure 6. (a) Adsorption and photocatalytic degradation of various organic dyes over sepiolite as a function of time; (b) removal efficiency of various organic dyes over sepiolite after $120 \mathrm{~min}$; (c) pseudo-first-order kinetic plot of various organic dyes over sepiolite; and (d) time-dependent changes in UV-Vis spectra of rhodamine B (RhB) in suspension of sepiolite under the visible light irradiation.

Figure $6 \mathrm{~b}$ summarized the final organic dye removal (\%) after 120 min of irradiation time under the visible light. The highest removal efficiency of MB was observed with $83.3 \%$, in which $61.5 \%$ was from adsorption and $21.7 \%$ was from photocatalytic degradation. The reason why RhB was less adsorbed on sepiolite despite the same charge as MB would be the larger molecular size of RhB than $\mathrm{MB}$ and the higher electron density localized in S of MB than $\mathrm{N}$ of RhB (Figure S1). Regarding of photocatalytic degradation, RhB was the most effectively photocatalytically-degraded, with $45.3 \%$. The lower photocatalytic performance of $\mathrm{MB}$ than $\mathrm{RhB}$ was caused by the shielding effect from supernumerary adsorbed dye molecules, which may have changed the rate of production of active species (e.g., ${ }^{\bullet} \mathrm{O}_{2}{ }^{-}$). Negligibly trace degradation was observed with anionic dyes (OII and TB), indicating photodegradation of dyes hardly happens without adsorption. 
To evaluate the kinetics of organic dye degradation over sepiolite, the degradation results after the visible light irradiation were fitted to pseudo-first-order equation (Equation (2)):

$$
-\ln \left(C / C_{0}\right)=k t
$$

where $C_{0}$ is the initial concentration of organic dye, $C$ is the remaining concentration of organic dye at time $t(\mathrm{~min})$, and $k$ is the pseudo-first-order rate constant $\left(\mathrm{min}^{-1}\right)$ [40-42]. The plots of reaction time $(t)$ versus $-\ln \left(C / C_{0}\right)$ provided a linear line, suggesting that the organic dye degradations were well fitted to the pseudo-first-order kinetic model, as shown in Figure $6 \mathrm{c}\left(R^{2}=0.9938\right.$ and 0.9956 for MB-V and RhB-V). In addition, it could be seen that the degradation rate constants under the visible light irradiation were greater than those under the dark conditions about 45 and 6 times in case of RhB and $\mathrm{MB}$, respectively, indicating a synergetic effect of cationic dye and sepiolite under visible light irradiation. Moreover, the synergistic effect was more excellent for the degradation of RhB than MB over sepiolite.

By focusing on the photocatalytic degradation of RhB on sepiolite, time-dependent UV-Vis absorption spectra were observed (Figure 6d). After photocatalytic degradation of RhB on sepiolite happened, the adsorption intensity clearly decreased around $554 \mathrm{~nm}$, and the absorption peak position of RhB had shifted to the lower wavenumbers, indicating that the degradation of ethyl groups in RhB occurred during the photocatalytic degradation [37,43-45]. Moreover, the decomposition of RhB was monitored over time by HPLC, as shown in Figure 7. The peak at $18.5 \mathrm{~min}$ of retention time was assigned to $\mathrm{RhB}$, and the peak intensity relatively decreased over time. A distinctive new peak at 14.6 min of retention time was observed within $30 \mathrm{~min}$ after photocatalytic degradation, and its intensity increased relatively with time. The other tiny peaks around $8.9 \mathrm{~min}$ and $11.8 \mathrm{~min}$ of the retention time were gradually observed over time. Appearance of the new peaks in HPLC was in accordance with the degradation of $\mathrm{RhB}$, which could be confirmed by the determination of the remaining RhB by UV-Vis spectrometry (Figure 6a) and the wavenumber-shift of an absorption peak in UV-Vis spectrum (Figure $6 \mathrm{~d}$ ). In the previous reports, $N$-deethylated byproducts ( $N, N$-diethyl- $N$-ethylrhodamine, $\mathrm{N}, \mathrm{N}$-diethylrhodamine, and $\mathrm{N}$-ethylrhodamine) were confirmed as byproducts in photocatalytic degradation of RhB using LC-MS [46-48], suggesting decomposition of ethyl groups from xanthene rings in the molecular structure of RhB.

After 120 min-photoreaction, XRD patterns and FTIR spectra for the solid resides were collected in the same manner as the pristine sepiolite (Figure 1). XRD patterns were mostly identical with the pristine sepiolite. In FTIR for the solid resides after reaction with MB, there were additional peaks in a region of 1300 to $1600 \mathrm{~cm}^{-1}$, which were assigned to the aromatic ring structure in MB molecule, and the peaks at $1500 \mathrm{~cm}^{-1}$ were attributed to $\mathrm{C}=\mathrm{N}$ stretching vibration mode (Figure $\mathrm{S} 1$ ). It was consistent with the largest amounts of MB, which were adsorbed on sepiolite (Figure 6b). In other FTIR spectra, there were no significant changes. These results supported that the photocatalytic reaction happened without any degradation of sepiolite.

The previous reports regarding of photocatalytic degradation of organic dyes using composites, including sepiolite, were summarized in Table 2 to compare with the present work. From the comparative results of dye degradation, we could clearly signify our research work from the reported results. In the previous reports, sepiolite was utilized as supporting material for known photocatalysts, such as $\mathrm{TiO}_{2}$, and showed $\sim 80 \% \mathrm{RhB}$ dye degradation, whereas we observed that pristine sepiolite material could show comparable degradation efficiency under visible light irradiation. We believe that the present finding might be useful for detailed understanding in the upcoming research scope of the sepiolite-based photocatalyst materials for organic dye degradation. 


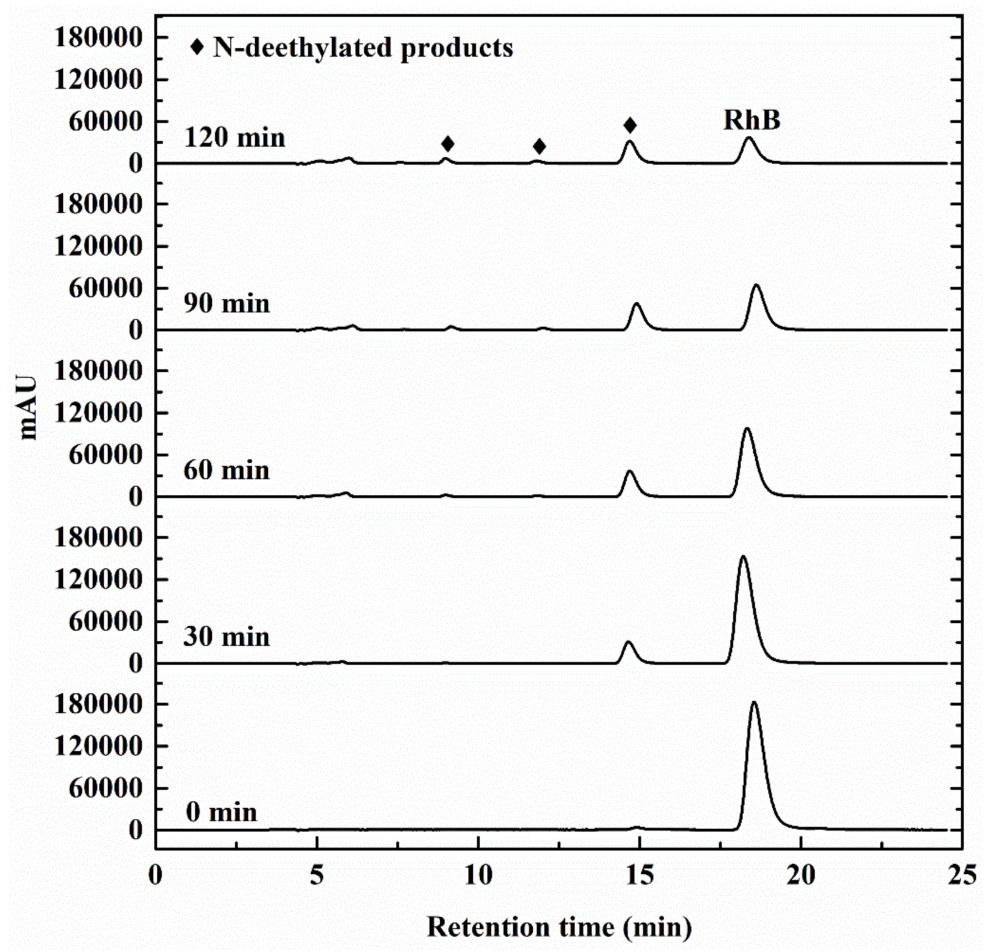

Figure 7. Time-dependent changes in HPLC spectra of RhB and degradation products on sepiolite under the visible light irradiation.

Table 2. Comparison of photocatalytic efficiency of sepiolite composites with other reported photocatalysts for organic dye degradation.

\begin{tabular}{|c|c|c|c|c|c|c|c|}
\hline Catalyst & $\begin{array}{c}\text { Active } \\
\text { Compound }\end{array}$ & Target & $\mathrm{C}_{0}(\mathrm{~mol} / \mathrm{L})$ & $\begin{array}{l}\text { Loading } \\
\text { (g/L) }\end{array}$ & $\begin{array}{c}\text { Efficacy } \\
(\%)\end{array}$ & $\begin{array}{l}\text { Time } \\
(\mathrm{min})\end{array}$ & Ref. \\
\hline $\mathrm{Bi}_{2} \mathrm{O}_{3} /$ sepiolite & $\mathrm{Bi}_{2} \mathrm{O}_{3}$ & $\begin{array}{l}\text { Malachite } \\
\text { green }\end{array}$ & $14 \times 10^{-5}$ & 0.5 & 98.2 & 180 & [49] \\
\hline Sepiolite- $\mathrm{TiO}_{2}$ & $\mathrm{TiO}_{2}$ & Orange G & $2.2 \times 10^{-5}$ & 0.8 & 97.8 & 150 & [50] \\
\hline Sepiolite/Cu $\mathbf{u}_{2} \mathrm{O} / \mathrm{Cu}$ & $\mathrm{Cu}_{2} \mathrm{O} / \mathrm{Cu}$ & Congo red & $1.4 \times 10^{-5}$ & 0.2 & 95.1 & 50 & [51] \\
\hline $\mathrm{Eu}-\mathrm{TiO}_{2} /$ sepiolite & $\mathrm{Eu}-\mathrm{TiO}_{2}$ & Orange G & $2.2 \times 10^{-5}$ & 0.8 & $\sim 70$ & 600 & [52] \\
\hline $\begin{array}{c}\mathrm{ZnCr} \\
\text { LDH/Sepiolite }\end{array}$ & $\mathrm{ZnCr} \mathrm{LDH}$ & $\mathrm{MB}$ & $3.1 \times 10^{-5}$ & 1.25 & 93.1 & 120 & [19] \\
\hline Sepiolite $-\mathrm{TiO}_{2}$ & $\mathrm{TiO}_{2}$ & RhB & $8.3 \times 10^{-5}$ & 0.85 & $\sim 80$ & 120 & [53] \\
\hline Sepiolite & $\begin{array}{l}\text { Adsorbed MB } \\
\text { on sepiolite }\end{array}$ & MB & $2.0 \times 10^{-5}$ & 0.25 & 83.3 & 120 & $\begin{array}{l}\text { This } \\
\text { work }\end{array}$ \\
\hline Sepiolite & $\begin{array}{l}\text { Adsorbed RhB } \\
\text { on sepiolite }\end{array}$ & RhB & $2.0 \times 10^{-5}$ & 0.25 & 65.5 & 120 & $\begin{array}{l}\text { This } \\
\text { work }\end{array}$ \\
\hline
\end{tabular}

\subsection{Radical Scavenger Test}

In order to elucidate the role of responsible reactive species for $\mathrm{RhB}$ degradation, several scavenger reagents were tested, as shown in Figure 8, where isopropyl alcohol (IPA), benzoquinone (BQ), and potassium iodide (KI) were used as the scavenger reagents for $\mathrm{h}^{+}, \bullet^{\bullet} \mathrm{O}_{2}{ }^{-}$, and ${ }^{\bullet} \mathrm{OH}$, respectively [54-57]. The photocatalytic degradation efficiency of RhB significantly decreased after trapping ${ }^{\bullet} \mathrm{O}_{2}{ }^{-}$by $\mathrm{BQ}$, but the presence of KI and IPA had shown negligibly small decreases in RhB degradation efficiency, indicating that ${ }^{\bullet} \mathrm{O}_{2}{ }^{-}$was dominantly responsible for the photocatalytic degradation of $\mathrm{RhB}$, but the $\mathrm{h}^{+}$ and $\bullet \mathrm{OH}$ did not play an important role in the degradation of RhB over sepiolite under the visible 
light irradiation. These results implied that ${ }^{\bullet} \mathrm{O}_{2}{ }^{-}$was the main oxidant species in the photocatalytic degradation of $\mathrm{RhB}$.

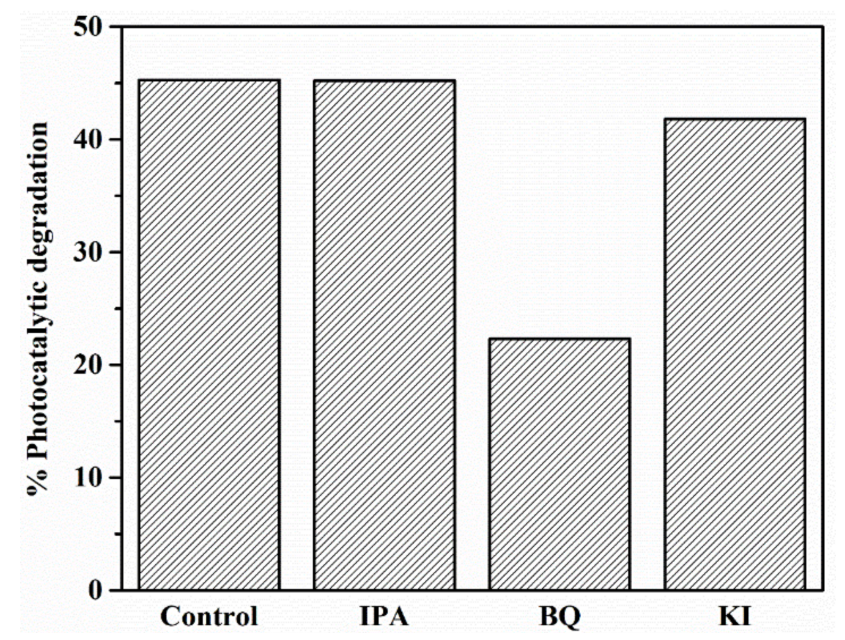

Figure 8. Photocatalytic degradation of RhB over sepiolite in the presence of different radical scavengers. IPA: isopropyl alcohol; BQ: benzoquinone; and KI: potassium iodide.

\subsection{Stability Test}

One of the important factors of photocatalyst material is stability. The photocatalytic stability of sepiolite for RhB degradation under visible light irradiation was examined by the recycling test three times. From the observed results in Figure 9, it could be seen that the photocatalytic efficiency of sepiolite for RhB degradation still maintained for three cycles, suggesting the sepiolite showed high stability for photocatalytic degradation of organic dye.

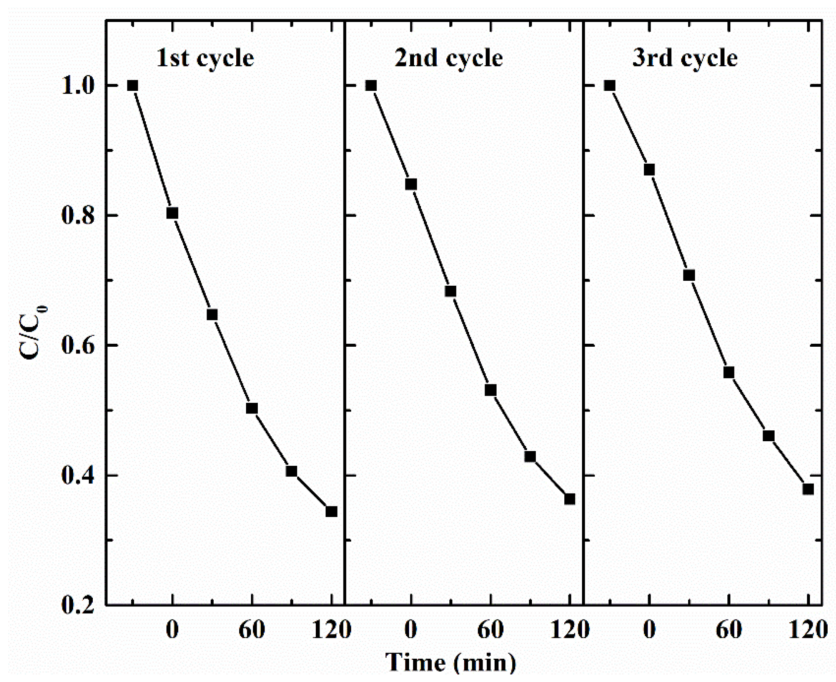

Figure 9. Recycling test in the photocatalytic degradation of $2 \times 10^{-5} \mathrm{M}$ RhB over sepiolite (catalyst loading $=0.25 \mathrm{~g} / \mathrm{L}$ ) under visible light irradiation.

Moreover, the reusability of spent sepiolite after adsorption of RhB for $30 \mathrm{~min}$ in dark condition without any pretreatment was examined by applying to photocatalytic degradation of an anionic dye, TB, under the visible light irradiation. TB can be utilized for staining of cells in cytotoxicity measurements due to the negative charge of TB. The removal efficiency of TB after $2 \mathrm{~h}$ was displayed in Figure 10. Little adsorption capacity ( 1\%) of TB was observed on sepiolite and spent RhB-sepiolite under the dark condition. However, after the visible light irradiation, the spent RhB-sepiolite 
shows greater than twice photocatalytic degradation than pristine sepiolite. This suggests that the $\mathrm{RhB}$ adsorbed on the surface of sepiolite enhanced the photocatalytic degradation of TB through photosensitization property of RhB-sepiolite. Based on the results, the sequential photodegradation of cationic and anionic dye molecules are possible on sepiolite under the visible light to contribute to green chemistry in dye-contaminated water treatment.

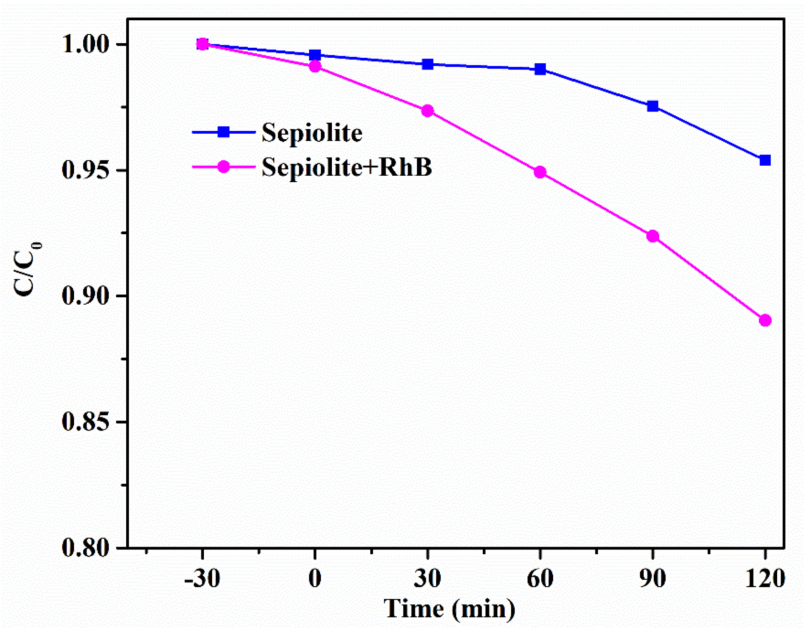

Figure 10. Removal efficiency of TB by sepiolite and spent RhB-sepiolite after adsorption of RhB under the visible light irradiation. The initial concentrations of RhB and TB were $2 \times 10^{-5} \mathrm{M}$.

\subsection{Mechanism of Organic Dye Degradation over Sepiolite}

The photosensitization of organic dye molecules is an important step for starting the photocatalytic reaction because the dye molecule can provide the electron to sepiolite through the photo-irradiation process [58-61]. In the case of RhB degradation over sepiolite under the visible light irradiation, the electron in the pristine sepiolite could not be excited under the visible light due to the wide energy band gap $(E g=3.7 \mathrm{eV}$, Figure $5 b)$. Firstly, cationic organic dye molecules (RhB) were adsorbed on the surface of the sepiolite, and then the electrons of $\mathrm{RhB}$ were excited under the visible light to generate the excited electrons. The electrons in the LUMO of RhB ( $E_{\mathrm{LUMO}}=-1.10 \mathrm{eV}$ versus NHE) were transferred to the $\mathrm{CB}$ of sepiolite $\left(E_{\mathrm{CB}}=-0.89 \mathrm{eV}\right)$ due to the more positive energy level of the CB of sepiolite, compared with LUMO state of RhB [62]. The photo-excited electron on the CB of sepiolite could reduce the dissolved $\mathrm{O}_{2}$ to ${ }^{\bullet} \mathrm{O}_{2}{ }^{-}$because the standard reduction potential of $\mathrm{O}_{2}$ to ${ }^{-} \mathrm{O}_{2}{ }^{-}\left(E^{0}\left(\mathrm{O}_{2} /{ }^{\bullet} \mathrm{O}_{2}{ }^{-}\right)=-0.046 \mathrm{eV}\right.$ versus NHE $\left.[63,64]\right)$ was more positive than the CB potential of sepiolite. Then, the oxidation of $\mathrm{RhB}$ by ${ }^{\bullet} \mathrm{O}_{2}{ }^{-}$occurred to degrade $\mathrm{RhB}$ to smaller molecules. Based on the above results, the mechanism for degradation of RhB over sepiolite under the visible light irradiation could be proposed as follows:

$$
\begin{gathered}
\mathrm{RhB} @ \text { sepiolite }+h v \rightarrow \mathrm{RhB}^{*}\left(\mathrm{~h}^{+}+\mathrm{e}^{-}\right) @ \text { sepiolite, } \\
\mathrm{RhB}^{*}\left(\mathrm{~h}^{+}+\mathrm{e}^{-}\right) @ \text { sepiolite } \rightarrow \mathrm{RhB}^{*}\left(\mathrm{~h}^{+}\right) @ \text { sepiolite }\left(\mathrm{e}^{-}\right), \\
\text {sepiolite }\left(\mathrm{e}^{-}\right)+\mathrm{O}_{2} \rightarrow{ }^{\bullet} \mathrm{O}_{2}^{-}, \\
\mathrm{O}_{2}{ }^{-}+\mathrm{RhB} \rightarrow \text { degradation products. }
\end{gathered}
$$

Aforesaid in Section 2.2, the obtained degradation results of anionic dyes (OII and TB) showed less degradation efficiency by using sepiolite. This was explained due to the less adsorption behavior of anionic dyes on the negative surface of sepiolite. This reconfirmed the role of adsorbed cationic dye, which is influenced by the dye photosensitized degradation mechanism. For the confirmation of this phenomena, the RhB adsorbed solid residual sepiolite from the dark conditions is further used for the degradation of anionic dye (TB) and showed better photocatalyst efficiency than pristine sepiolite. 
Here adsorbed RhB residue showed similar dye-sensitized mechanistic approach (as explained in Equations (3)-(5)) providing an electron to sepiolite and generated the ${ }^{\bullet} \mathrm{O}_{2}{ }^{-}$species responsible for the degradation of TB as in Equation (7):

$$
\mathrm{O}^{-}{ }^{-}+\mathrm{TB} \rightarrow \text { degradation products. }
$$

According to the above sequence, photocatalytic degradation mechanisms of organic dye (both cationic and anionic dyes) over sepiolite under the visible light irradiation, as illustrated in Scheme 1. Consequently, the cooperative function through the combination of cationic organic dye molecules with sepiolite through electrostatic interaction resulted in the improved photocatalytic degradation of organic dye molecules. The electrostatic interaction of cationic organic dye (i.e., RhB) with sepiolite was much more favorable than anionic dye (i.e., TB). Although anionic dye was less favorable for adsorption on sepiolite, a small amount of adsorbed anionic dye would still have been involved in photocatalytic degradation by ${ }^{\bullet} \mathrm{O}_{2}{ }^{-}$species on the surface of the sepiolite.

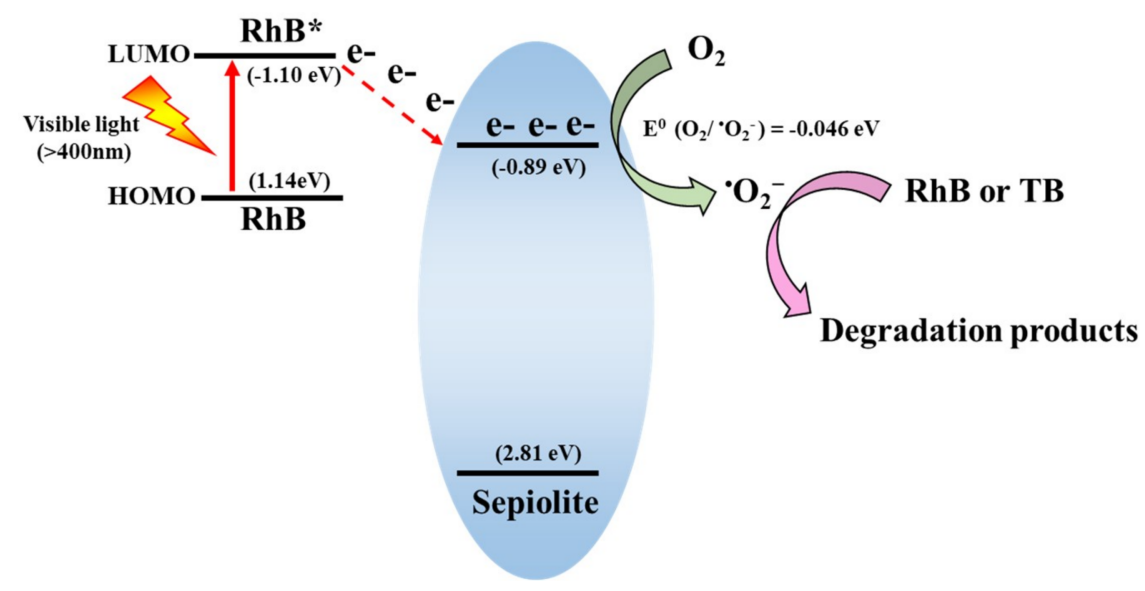

Scheme 1. Proposed mechanism of photocatalytic degradation RhB over sepiolite and TB over spent sepiolite after adsorption of RhB under the visible light irradiation.

\section{Materials and Methods}

\subsection{Materials and Reagents}

Sepiolite $(13 \% \mathrm{Mg}, \leq 10 \%$ loss on drying) was obtained from Sigma Aldrich Japan Co. Ltd (Tokyo, Japan) with the color of grayish white. $\mathrm{RhB}\left(\mathrm{C}_{28} \mathrm{H}_{31} \mathrm{ClN}_{2} \mathrm{O}_{3}, 97 \%\right.$ dye content, $\mathrm{RhB}$ ) was also obtained from Sigma Aldrich Japan. $\mathrm{MB}\left(\mathrm{C}_{16} \mathrm{H}_{18} \mathrm{~N}_{3} \mathrm{SCl} \cdot 3 \mathrm{H}_{2} \mathrm{O}, \mathrm{MB}\right)$ was purchased from Waldeck $\mathrm{GmbH} \&$ Co. KG (Münster, Germany). Orange II $\left(\mathrm{C}_{16} \mathrm{H}_{11} \mathrm{~N}_{2} \mathrm{NaO}_{4} \mathrm{~S}\right.$, OII $)$ and $\mathrm{TB}\left(\mathrm{C}_{34} \mathrm{H}_{28} \mathrm{~N}_{6} \mathrm{O}_{14} \mathrm{~S}_{4}, \mathrm{~TB}\right)$ were purchased from Wako Chemicals (Osaka, Japan). The chemicals were directly utilized without further purification. Ultrapure water was used in the preparation of the organic dye solutions and their experiments.

\subsection{Characterization}

The crystal phases of the original and spent sepiolite after photocatalytic reactions were characterized by powder X-ray diffraction (PXRD) on Ultima IV diffractometer (Rigaku, Akshima, Japan), using $\mathrm{Cu} \mathrm{K \alpha}$ radiation with $40 \mathrm{kV}$ acceleration voltage and $40 \mathrm{~mA}$ applied current at a $2^{\circ} / \mathrm{min}$ scanning speed and $0.02^{\circ}$ step size. The elemental compositions of sepiolite were determined by $\mathrm{X}$-ray fluorescence (XRF) spectroscopy Rigaku ZSX Primus II in the wavelength dispersive mode (Akishima, Japan). The functional groups of pristine sepiolite and spent sepiolite after the photocatalytic reaction were characterized by FTIR on Jasco FTIR-670 Plus (Tokyo, Japan). TEM images of the solid products were observed on a transmission electron microscope (JEM-2100HCKM, JEOL (Akishima, Japan). 
The X-ray photoelectron spectrum (XPS) for the original sepiolite was collected on an ESCA 5800 (ULVAC-PHI, Inc. Kanagawa, Japan) using a monochromated Al K $\alpha$ X-ray source at $200 \mathrm{~W}$. The data analysis was performed by Casa XPS software (version 2.3.12.8). Binding energy was calibrated using $E_{\mathrm{B}}(\mathrm{C} 1 \mathrm{~s})=284.6 \mathrm{eV}$ assigned to the contamination peak derived from vacuum oil in the apparatus. To estimate the band gap energy (Eg) of sepiolite, UV-Vis/DRS was applied using a Shimadzu UV-2450 spectrophotometer equipped with ISR-2200 integrating sphere attachment (Kyoto, Japan). The degradation products were determined on a Jasco LC-netII/ADC HPLC system PU-2089 plus pump, C0-2065 plus column oven, and UV-2075 plus detector equipped with a C18 column (K009450, Shodex, Japan). The mobile phase was prepared by mixing deionized water and methanol with the volumetric ratio of 3:7. The specific surface area (SSA) and pore size distribution of sepiolite were determined by Japan BEL-Max, BEL (Osaka, Japan).

\subsection{Photocatalytic Activity}

Photocatalytic performances were evaluated toward the photocatalytic degradation of various organic dyes under the visible light $(\lambda>400 \mathrm{~nm}$ ) irradiation (Scheme 2). Typically, $50 \mathrm{mg}$ of sepiolite powder was magnetically stirred in $50 \mathrm{~mL}$ of $2 \times 10^{-5} \mathrm{M}$ organic dye aqueous solution in the dark condition for $30 \mathrm{~min}$ to reach the adsorption-desorption equilibrium. The suspensions were then irradiated using a $500 \mathrm{~W}$ Xe lamp with a cut-off filter. During the light illumination, solutions were collected and filtrated by $0.45 \mu \mathrm{m}$ membrane filters to remove the suspended particles. The concentrations of the remaining organic dyes of $\mathrm{MB}, \mathrm{RhB}, \mathrm{OII}$, and TB were determined by UV-Vis spectrometry at $665,554,483$, and $575 \mathrm{~nm}$, respectively. Moreover, photocatalytic stability of sepiolite for RhB degradation under visible light irradiation was examined by the recycling test for three cycles. After every cycle, the spent sepiolite was separated from the suspension by centrifugation, followed by a wash with ethanol and water three times to remove covered, unreacted $\mathrm{RhB}$ and degradation products. The spent sepiolite was dried and used in the next cycle under identical photocatalytic experiment.

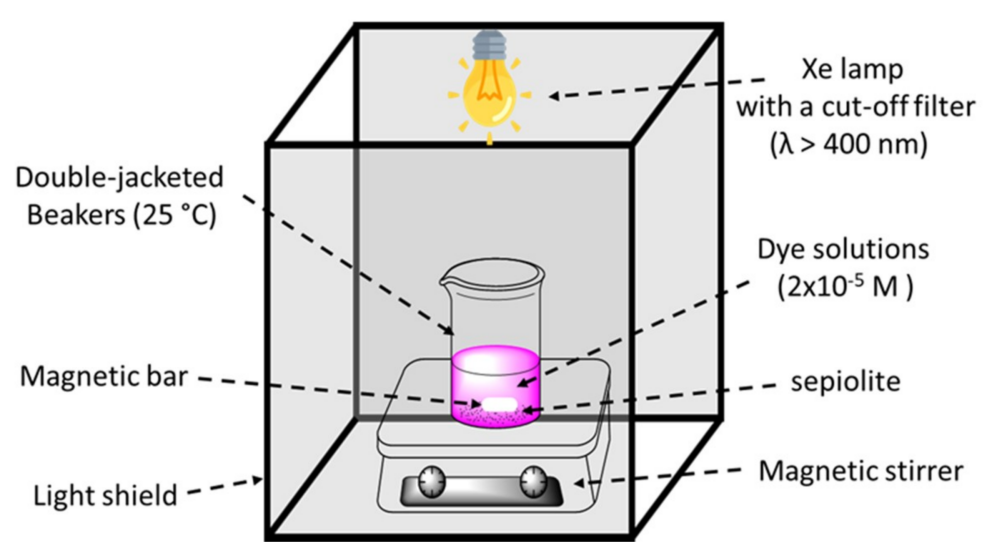

Scheme 2. Schematic of the photocatalytic experimental setup.

\section{Conclusions}

In the present work, we reported the photocatalytic activity of natural sepiolite by the dye-sensitized process to degrade organic dyes under the visible light irradiation. The photocatalytic activity of sepiolite was shown through electrostatistic coverage on the surface of sepiolite by the cationic organic dye compound. The role of covered cationic organic dye molecules on the surface of sepiolite was to produce the excited electrons under the visible light. Then the electrons could be transferred to $C B$ of sepiolite, enhancing the photocatalytic degradation efficiency of organic dyes mainly through oxidation by ${ }^{\bullet} \mathrm{O}_{2}{ }^{-}$which was generated by reduction of $\mathrm{O}_{2}$. The function of RhB-adsorbed sepiolite in the system is called as "photosensitizer". RhB was the most efficiently 
photo-degraded on the sepiolite compared with $\mathrm{MB}, \mathrm{TB}$, and OII. All the kinetic data of removal of $\mathrm{RhB}, \mathrm{MB}, \mathrm{TB}$, and $\mathrm{OII}$ on sepiolite were fitted to the pseudo-first-order reaction model. The greatest kinetic constant was found with RhB. The photocatalytic degradation of RhB on sepiolite under the visible light irradiation could be explained by adsorption and $E_{\mathrm{LUMO}}$ and $E_{\mathrm{HOMO}}$ in RhB. The spent sepiolite after adsorption of RhB successfully acted to photocatalytically degrade even anionic organic dye (TB) through dye-sensitization of RhB on sepiolite. Especially, we confirmed that the natural sepiolite represents a new class of visible light-responsive photocatalyst from naturally occurring minerals. It is unique as it absorbs visible light without modification. The acceptable performance with regard to photocatalytic activity and its low-cost characteristics make it a suitable candidate for application in environmental treatments.

Supplementary Materials: The following are available online at http://www.mdpi.com/2073-4344/9/3/235/s1, Figure S1: Chemical structures of dyes: (a) methylene blue (MB); (b) Rhodamine B (RhB); (c) Orange II (OII); (d) trypan Blue (TB).

Author Contributions: Conceptualization, K.S.; Methodology, C.C. and R.P.; Data curation, C.C. and R.P.; Writing-original draft preparation, C.C. and R.P.; Writing-review and editing, K.S., C.C. and R.P.; Supervision, K.S.; Project administration, K.S., C.C. and R.P.; Funding acquisition, K.S.

Funding: This work was supported to KS by Japan Society for the Promotion of Science (JSPS) KAKENHI Grant Numbers JP16H02435 and JP17F17355.

Conflicts of Interest: The authors declare no conflict of interest.

\section{References}

1. Sun, A.; Delacaillerie, J.B.D.; Fripiat, J.J. A New Microporous Material-Aluminated Sepiolite. Microporous Mater. 1995, 5, 135-142. [CrossRef]

2. Rytwo, G.; Nir, S.; Crespin, M.; Margulies, L. Adsorption and Interactions of Methyl Green with Montmorillonite and Sepiolite. J. Colloid Interface Sci. 2000, 222, 12-19. [CrossRef] [PubMed]

3. Jacobo-Azuara, A.; Ramos, R.; Padilla, E.; Aragon-Piña, A.; Maria Guerrero-Coronado, R.; Mendoza-Barron, J. Adsorption of heavy metals on Sepiolite 2011. Adsorpt. Sci. Technol. 2014, 29, 569-584.

4. Ozdemir, Y.; Dogan, M.; Alkan, M. Adsorption of cationic dyes from aqueous solutions by sepiolite. Microporous Mesoporous Mater. 2006, 96, 419-427. [CrossRef]

5. Bergaya, F.; Lagaly, G. Chapter 1 General Introduction: Clays, Clay Minerals, and Clay Science; Elsevier: Amsterdam, The Netherlands, 2006; Volume 1.

6. Liu, J.; Zhang, G. Recent advances in synthesis and applications of clay-based photocatalysts: A review. Phys. Chem. Chem. Phys. PCCP 2014, 16, 8178-8192. [CrossRef] [PubMed]

7. Álvarez, A.; Santaren, J.; Esteban, A. Current Industrial Applications of Palygorskite and Sepiolite; Elsevier: Amsterdam, The Netherlands, 2011; Volume 3, p. 281.

8. Alvarez, A. Sepiolite: Properties and Uses. In Developments in Sedimentology; Singer, A., Galan, E., Eds.; Elsevier: Amsterdam, The Netherlands, 1984; Volume 37, pp. 253-287.

9. Murray, H.H. Overview-Clay mineral applications. Appl. Clay Sci. 1991, 5, 379-395. [CrossRef]

10. Ruiz-Hitzky, E.; Aranda, P.; Álvarez, A.; Santarén, J.; Esteban-Cubillo, A. Chapter 17-Advanced Materials and New Applications of Sepiolite and Palygorskite. In Developments in Clay Science; Galàn, E., Singer, A., Eds.; Elsevier: Amsterdam, The Netherlands, 2011; Volume 3, pp. 393-452.

11. Guggenheim, S.; Krekeler, M.P.S. Chapter 1-The Structures and Microtextures of the Palygorskite-Sepiolite Group Minerals. In Developments in Clay Science; Galàn, E., Singer, A., Eds.; Elsevier: Amsterdam, The Netherlands, 2011; Volume 3, pp. 3-32.

12. Cecilia, J.A.; Vilarrasa-Garcia, E.; Cavalcante, C.L.; Azevedo, D.C.S.; Franco, F.; Rodriguez-Castellon, E. Evaluation of two fibrous clay minerals (sepiolite and palygorskite) for $\mathrm{CO}_{2}$ Capture. J. Environ. Chem. Eng. 2018, 6, 4573-4587. [CrossRef]

13. Brigatti, M.F.; Galan, E.; Theng, B.K.G. Chapter 2 Structures and Mineralogy of Clay Minerals. In Developments in Clay Science; Bergaya, F., Theng, B.K.G., Lagaly, G., Eds.; Elsevier: Amsterdam, The Netherlands, 2006; Volume 1, pp. 19-86. 
14. Brigatti, M.; Malferrari, D.; Laurora, A.; Elmi, C. Structure and Mineralogy of Layer Silicates: Recent Perspectives and New Trends; Mineralogical Society of Great Britain: London, UK, 2011; Volume 12, pp. 1-71.

15. Hu, X.; Sun, Z.; Song, J.; Zhang, G.; Li, C.; Zheng, S. Synthesis of novel ternary heterogeneous $\mathrm{BiOCl} / \mathrm{TiO}_{2} /$ sepiolite composite with enhanced visible-light-induced photocatalytic activity towards tetracycline. J. Colloid Interface Sci. 2019, 533, 238-250. [CrossRef] [PubMed]

16. Kaur, S.; Singh, V. Visible light induced sonophotocatalytic degradation of Reactive Red dye 198 using dye sensitized $\mathrm{TiO}_{2}$. Ultrason. Sonochem. 2007, 14, 531-537. [CrossRef] [PubMed]

17. Zhang, Y.L.; Wang, D.J.; Zhang, G.K. Photocatalytic degradation of organic contaminants by $\mathrm{TiO}_{2} / \mathrm{sepiolite}$ composites prepared at low temperature. Chem. Eng. J. 2011, 173, 1-10. [CrossRef]

18. Ugurlu, M.; Karaoglu, M.H. TiO 2 supported on sepiolite: Preparation, structural and thermal characterization and catalytic behaviour in photocatalytic treatment of phenol and lignin from olive mill wastewater. Chem. Eng. J. 2011, 166, 859-867. [CrossRef]

19. Jin, L.; Zeng, H.Y.; Xu, S.; Chen, C.R.; Duan, H.Z.; Du, J.Z.; Hu, G.; Sun, Y.X. Facile preparation of sepiolite@LDH composites for the visible-light degradation of organic dyes. Chin. J. Catal. 2018, 39, 1832-1841. [CrossRef]

20. Akkari, M.; Aranda, P.; Belver, C.; Bedia, J.; Ben Haj Amara, A.; Ruiz-Hitzky, E. ZnO/sepiolite heterostructured materials for solar photocatalytic degradation of pharmaceuticals in wastewater. Appl. Clay Sci. 2018, 156, 104-109. [CrossRef]

21. Akkari, M.; Aranda, P.; Mayoral, A.; Garcia-Hernandez, M.; Ben Haj Amara, A.; Ruiz-Hitzky, E. Sepiolite nanoplatform for the simultaneous assembly of magnetite and zinc oxide nanoparticles as photocatalyst for improving removal of organic pollutants. J. Hazard. Mater. 2017, 340, 281-290. [CrossRef] [PubMed]

22. Xu, W.G.; Liu, S.F.; Lu, S.X.; Kang, S.Y.; Zhou, Y.; Zhang, H.F. Photocatalytic degradation in aqueous solution using quantum-sized $\mathrm{ZnO}$ particles supported on sepiolite. J. Colloid Interface Sci. 2010, 351, $210-216$. [CrossRef] [PubMed]

23. Giustetto, R.; Seenivasan, K.; Bonino, F.; Ricchiardi, G.; Bordiga, S.; Chierotti, M.R.; Gobetto, R. Host/Guest Interactions in a Sepiolite-Based Maya Blue Pigment: A Spectroscopic Study. J. Phys. Chem. C 2011, 115, 16764-16776. [CrossRef]

24. Bhatt, A.S.; Sakaria, P.L.; Vasudevan, M.; Pawar, R.R.; Sudheesh, N.; Bajaj, H.C.; Mody, H.M. Adsorption of an anionic dye from aqueous medium by organoclays: Equilibrium modeling, kinetic and thermodynamic exploration. RSC Adv. 2012, 2, 8663-8671. [CrossRef]

25. Rodriguez, A.; Ovejero, G.; Mestanza, M.; Garcia, J. Removal of Dyes from Wastewaters by Adsorption on Sepiolite and Pansil. Ind. Eng. Chem. Res. 2010, 49, 3207-3216. [CrossRef]

26. Wang, P.; Cheng, M.M.; Zhang, Z.H. On different photodecomposition behaviors of rhodamine B on laponite and montmorillonite clay under visible light irradiation. J. Saudi Chem. Soc. 2014, 18, 308-316. [CrossRef]

27. Hassan, M.; Afify, A.S.; Tulliani, J.M. Synthesis of ZnO Nanoparticles onto Sepiolite Needles and Determination of Their Sensitivity toward Humidity, $\mathrm{NO}_{2}$ and $\mathrm{H}_{2}$. J. Mater. Sci. Technol. 2016, 32, 573-582. [CrossRef]

28. Pawar, R.R.; Lalhmunsiama; Bajaj, H.C.; Lee, S.-M. Activated bentonite as a low-cost adsorbent for the removal of $\mathrm{Cu}(\mathrm{II})$ and $\mathrm{Pb}(\mathrm{II})$ from aqueous solutions: Batch and column studies. J. Ind. Eng. Chem. 2016, 34, 213-223. [CrossRef]

29. Pawar, R.R.; Gupta, P.; Lalhmunsiama; Bajaj, H.C.; Lee, S.-M. Al-intercalated acid activated bentonite beads for the removal of aqueous phosphate. Sci. Total Environ. 2016, 572, 1222-1230. [CrossRef] [PubMed]

30. Krekeler, M.P.S.; Guggenheim, S. Defects in microstructure in palygorskite-sepiolite minerals: A transmission electron microscopy (TEM) study. Appl. Clay Sci. 2008, 39, 98-105. [CrossRef]

31. Sing, K.S.W.; Williams, R.T. Physisorption Hysteresis Loops and the Characterization of Nanoporous Materials. Adsorpt. Sci. Technol. 2004, 22, 773-782. [CrossRef]

32. Sing, K.S.W.; Everett, D.H.; Haul, R.A.W.; Moscou, L.; Pierotti, R.A.; Rouquérol, J.; Siemieniewska, T. Reporting Physisorption Data for Gas/Solid Systems with Special Reference to the Determination of Surface Area and Porosity. Pure Appl. Chem. 1985, 57, 603-619. [CrossRef]

33. Pawar, R.R.; Kevadiya, B.D.; Brahmbhatt, H.; Bajaj, H.C. Template free synthesis of mesoporous hectorites: Efficient host for $\mathrm{pH}$ responsive drug delivery. Int. J. Pharm. 2013, 446, 145-152. [CrossRef] [PubMed]

34. Pawar, R.R.; Patel, H.A.; Sethia, G.; Bajaj, H.C. Selective adsorption of carbon dioxide over nitrogen on calcined synthetic hectorites with tailor-made porosity. Appl. Clay Sci. 2009, 46, 109-113. [CrossRef] 
35. Hubbard, B.; Kuang, W.; Moser, A.; Facey, G.A.; Detellier, C. Structural study of maya blue: Textural, thermal and solid-state multinuclear magnetic resonance characterization of the palygorskite-indigo and sepiolite-indigo adducts. Clays Clay Miner. 2003, 51, 318-326. [CrossRef]

36. Dong, F.; Zhao, Z.; Xiong, T.; Ni, Z.; Zhang, W.; Sun, Y.; Ho, W.K. In situ construction of g-C $\mathrm{C}_{3} \mathrm{~N}_{4} / \mathrm{g}-\mathrm{C}_{3} \mathrm{~N}_{4}$ metal-free heterojunction for enhanced visible-light photocatalysis. ACS Appl. Mater. Interfaces 2013, 5, 11392-11401. [CrossRef] [PubMed]

37. Su, X.D.; Yang, J.J.; Yu, X.; Zhu, Y.; Zhang, Y.M. In situ grown hierarchical 50\%BiOCl/BiOI hollow flowerlike microspheres on reduced graphene oxide nanosheets for enhanced visible-light photocatalytic degradation of rhodamine B. Appl. Surf. Sci. 2018, 433, 502-512. [CrossRef]

38. Li, Z.; Chen, M.; Ai, Z.Q.; Wu, L.; Zhang, Q.W. Mechanochemical synthesis of CdS/MgAl LDH-precursor as improved visible-light driven photocatalyst for organic dye. Appl. Clay Sci. 2018, 163, 265-272. [CrossRef]

39. Wan, C.; Chen, B. Synthesis and characterization of biomimetic hydroxyapatite/sepiolite nanocomposites. Nanoscale 2011, 3, 693-700. [CrossRef] [PubMed]

40. Feng, Q.; Li, S.Y.; Ma, W.H.; Fan, H.J.; Wan, X.H.; Lei, Y.; Chen, Z.J.; Yang, J.; Qin, B. Synthesis and characterization of $\mathrm{Fe}_{3} \mathrm{O}_{4} / \mathrm{ZnO}-\mathrm{GO}$ nanocomposites with improved photocatalytic degradation methyl orange under visible light irradiation. J. Alloy. Compd. 2018, 737, 197-206. [CrossRef]

41. Wei, Z.; Benlin, D.; Fengxia, Z.; Xinyue, T.; Jiming, X.; Lili, Z.; Shiyin, L.; Leung, D.Y.C.; Sun, C. A novel 3D plasmonic p-n heterojunction photocatalyst: $\mathrm{Ag}$ nanoparticles on flower-like $\mathrm{p}-\mathrm{Ag}_{2} \mathrm{~S} / \mathrm{n}-\mathrm{BiVO}_{4}$ and its excellent photocatalytic reduction and oxidation activities. Appl. Catal. B Environ. 2018, 229, 171-180. [CrossRef]

42. Xu, F.; Chen, H.; Xu, C.; Wu, D.; Gao, Z.; Zhang, Q.; Jiang, K. Ultra-thin $\mathrm{Bi}_{2} \mathrm{WO}_{6}$ porous nanosheets with high lattice coherence for enhanced performance for photocatalytic reduction of $\mathrm{Cr}(\mathrm{VI})$. J. Colloid Interface Sci. 2018, 525, 97-106. [CrossRef] [PubMed]

43. Zhang, D. Effectiveness of photodecomposition of rhodamine B and malachite green upon coupled tricomponent $\mathrm{TiO}_{2}$ (Anatase-Rutile)/ZnO nanocomposite. Acta Chim. Slovaca 2013, 6, 245-255. [CrossRef]

44. Halterman, R.L.; Moore, J.L.; Mannel, L.M. Disrupting aggregation of tethered rhodamine B dyads through inclusion in cucurbit [7] uril. J. Org. Chem. 2008, 73, 3266-3269. [CrossRef] [PubMed]

45. Pica, M.; Calzuola, S.; Donnadio, A.; Gentili, P.; Nocchetti, M.; Casciola, M. De-Ethylation and Cleavage of Rhodamine B by a Zirconium Phosphate/Silver Bromide Composite Photocatalyst. Catalysts 2018, 9, 3. [CrossRef]

46. Zhang, W.; Xing, J.; Yang, Z.; Kong, M.; Yao, H. A chemical etching route to controllable fabrication of $\mathrm{TiO}_{2}$ hollow nanospheres for enhancing their photocatalytic activity. Front. Chem. Sci. Eng. 2013, 7, $192-201$. [CrossRef]

47. Yu, K.; Yang, S.; He, H.; Sun, C.; Gu, C.; Ju, Y. Visible light-driven photocatalytic degradation of rhodamine B over $\mathrm{NaBiO}_{3}$ : Pathways and mechanism. J. Phys. Chem. A 2009, 113, 10024-10032. [CrossRef] [PubMed]

48. Hu, X.; Mohamood, T.; Ma, W.; Chen, C.; Zhao, J. Oxidative decomposition of rhodamine B dye in the presence of $\mathrm{VO}_{2}{ }^{+}$and/or $\mathrm{Pt}(\mathrm{IV})$ under visible light irradiation: N-deethylation, chromophore cleavage, and mineralization. J. Phys. Chem. B 2006, 110, 26012-26018. [CrossRef] [PubMed]

49. Guishui, L.; Lijun, C.; Bing, Z.; Yi, L. Novel $\mathrm{Bi}_{2} \mathrm{O}_{3}$ loaded sepiolite photocatalyst: Preparation and characterization. Mater. Lett. 2016, 168, 143-145. [CrossRef]

50. Zhou, F.; Yan, C.; Liang, T.; Sun, Q.; Wang, H. Photocatalytic degradation of Orange G using sepiolite-TiO nanocomposites: Optimization of physicochemical parameters and kinetics studies. Chem. Eng. Sci. 2018, 183, 231-239. [CrossRef]

51. Wang, P.; Qi, C.; Hao, L.; Wen, P.; Xu, X. Sepiolite $/ \mathrm{Cu}_{2} \mathrm{O} / \mathrm{Cu}$ photocatalyst: Preparation and high performance for degradation of organic dye. J. Mater. Sci. Technol. 2019, 35, 285-291. [CrossRef]

52. Zhou, F.; Yan, C.; Sun, Q.; Komarneni, S. $\mathrm{TiO}_{2} /$ Sepiolite nanocomposites doped with rare earth ions: Preparation, characterization and visible light photocatalytic activity. Microporous Mesoporous Mater. 2019, 274, 25-32. [CrossRef]

53. Papoulis, D.; Panagiotaras, D.; Tsigrou, P.; Christoforidis, K.C.; Petit, C.; Apostolopoulou, A.; Stathatos, E.; Komarneni, S.; Koukouvelas, I. Halloysite and sepiolite $-\mathrm{TiO}_{2}$ nanocomposites: Synthesis characterization and photocatalytic activity in three aquatic wastes. Mater. Sci. Semicond. Process. 2018, 85, 1-8. [CrossRef] 
54. Hernández-Uresti, D.B.; Vázquez, A.; Sanchez-Martinez, D.; Obregón, S. Performance of the polymeric g- $\mathrm{C}_{3} \mathrm{~N}_{4}$ photocatalyst through the degradation of pharmaceutical pollutants under UV-vis irradiation. $J$. Photochem. Photobiol. A Chem. 2016, 324, 47-52. [CrossRef]

55. Luo, B.; Chen, M.; Zhang, Z.; Xu, J.; Li, D.; Xu, D.; Shi, W. Highly efficient visible-light-driven photocatalytic degradation of tetracycline by a Z-scheme $\mathrm{g}-\mathrm{C}_{3} \mathrm{~N}_{4} / \mathrm{Bi}_{3} \mathrm{TaO}_{7}$ nanocomposite photocatalyst. Dalton Trans 2017, 46, 8431-8438. [CrossRef] [PubMed]

56. Hou, C.; Hu, B.; Zhu, J. Photocatalytic Degradation of Methylene Blue over $\mathrm{TiO}_{2}$ Pretreated with Varying Concentrations of NaOH. Catalysts 2018, 8, 575. [CrossRef]

57. Wang, L.; Zhang, C.; Cheng, R.; Ali, J.; Wang, Z.; Mailhot, G.; Pan, G. Microcystis aeruginosa Synergistically Facilitate the Photocatalytic Degradation of Tetracycline Hydrochloride and $\mathrm{Cr}(\mathrm{VI})$ on $\mathrm{PAN} / \mathrm{TiO}_{2} / \mathrm{Ag}$ Nanofiber Mats. Catalysts 2018, 8, 628. [CrossRef]

58. Bai, Z.Q.; Liu, Z.W. A broadband photodetector based on Rhodamine B-sensitized ZnO nanowires film. Sci. Rep. 2017, 7, 11384. [CrossRef] [PubMed]

59. Le, T.T.; Akhtar, M.S.; Park, D.M.; Lee, J.C.; Yang, O.B. Water splitting on Rhodamine-B dye sensitized Co-doped $\mathrm{TiO}_{2}$ catalyst under visible light. Appl. Catal. B Environ. 2012, 111, 397-401. [CrossRef]

60. Zhao, H.P.; Zhang, Y.F.; Li, G.F.; Tian, F.; Tang, H.; Chen, R. Rhodamine B-sensitized BiOCl hierarchical nanostructure for methyl orange photodegradation. RSC Adv. 2016, 6, 7772-7779. [CrossRef]

61. Molla, M.A.I.; Tateishi, I.; Furukawa, M.; Katsumata, H.; Suzuki, T.; Kaneco, S. Photocatalytic Decolorization of Dye with Self-Dye-Sensitization under Fluorescent Light Irradiation. ChemEngineering 2017, 1, 8. [CrossRef]

62. Ruankham, P.; Sae-Kung, C.; Mangkorntong, N.; Mangkorntong, P.; Choopun, S. Photoelectrochemical Characteristic of ZnO Dye-sensitized Solar Cell with Platinum Nanoparticle as a Counterelectrode. CMU J. Nat. Sci. 2008, 7, 177.

63. Huang, S.; Chen, J.; Zhong, J.; Li, J.; Hu, W.; Li, M.; Huang, K.; Duan, R. Enhanced photocatalytic performance of $\mathrm{Ag} / \mathrm{AgCl} / \mathrm{SnO}_{2}$ originating from efficient formation of ${ }^{\mathrm{O}_{2}}{ }^{-}$. Mater. Chem. Phys. 2017, 201, $35-41$. [CrossRef]

64. Watanabe, M. Dye-sensitized photocatalyst for effective water splitting catalyst. Sci. Technol. Adv. Mater. 2017, 18, 705-723. [CrossRef] [PubMed]

(c) 2019 by the authors. Licensee MDPI, Basel, Switzerland. This article is an open access article distributed under the terms and conditions of the Creative Commons Attribution (CC BY) license (http:/ / creativecommons.org/licenses/by/4.0/). 